\title{
Radiology
}

\section{Characterization of the Foramen Magnum in a Sudanese Population Using Computed Tomography}

\author{
Ikhlas Abdelaziz ${ }^{1,2 *}$; Salem Saeed Alghamdi'; Abubakr Haroun²; Mohammed Yousef ${ }^{3}$; \\ Abdulrahman Tajaldeen ${ }^{4}$; Rowa Aljondi'; Somayah Alghamdi ${ }^{5}$; Mogahid Zidan ${ }^{6}$ \\ ${ }^{1}$ University of Jeddah, College of Applied Medical Sciences, Jeddah, Saudi Arabia \\ ${ }^{2}$ College of Medical Radiological Sciences, Sudan University of Science and Technology, Khartoum, Sudan \\ ${ }^{3}$ Batterjee Medical College, Jeddah, Saudi Arabia \\ ${ }^{4}$ College of Applied Medical Science, Imam Abdulrahman Bin Faisal University, \\ Dammam, Saudi Arabia \\ ${ }^{5}$ King Abdulaziz University Hospital, Jeddah, Saudi Arabia \\ ${ }^{6}$ Al-Ghad International College for Applied Medical Science, Abha, Saudi Arabia
}

\begin{abstract}
Background: The aim of this study is to use CT images to characterize the foramen magnum (FM) in a sample of Sudanese participants and examine the effect on FM diameters of patient height and the diameter of the base of the skull to help predict pathological conditions according to organ size.

Methods and Results: This study was conducted between January 2016 and March 2016 and included 50 patients $(60 \%$ male and $40 \%$ female, aged between 20 and 85 years) with normal cranial CT images. The mean values of the FM sagittal diameter (FMSD) for female and male subjects were $35.80 \pm 2.88 \mathrm{~mm}$ and $37.41 \pm 3.27 \mathrm{~mm}$, respectively. The mean values of the FM transverse diameter (FMTD) for female and male subjects were $28.8 \pm 1.96 \mathrm{~mm}$ and $30.93 \pm 2.95 \mathrm{~mm}$, respectively. A weak direct correlation was found between FMSD and the length of the base of the skull $(\mathrm{r}=0.177)$, indicating that the diameter of the base of the skull is related to the measurement of the FM. Weak direct correlations were also found between patient height and FMSD $(\mathrm{r}=0.023)$ and patient height and BSL $(\mathrm{r}=0.044)$.

Conclusion: The effect of the diameter of the base of the skull on the FM diameters was very weak. There was a relationship between FMSD and patient height, although this correlation was weak.(International Journal of Biomedicine. 2020;10(3):221-225.)
\end{abstract}

Key Words: foramen magnum $\bullet$ base of the skull $\bullet$ computed tomography

\section{Introduction}

The foramen magnum (FM) is a large circular opening in the occipital bone of the human skull. ${ }^{(1,2)}$ It is one of several oval openings (foramina) in the skull's base, and the spinal cord, an extension of the medulla, passes through the FM as it exits the cranial vault. Apart from the transmission of the medulla oblongata and its membranes, ${ }^{(1,2)}$ the FM transmits the vertebral arteries, anterior and posterior spinal arteries, tectorial

*Corresponding author: Dr. Ikhlas Abdelaziz, Department of Medicine Imaging and Radiation Sciences, College of Applied Medical Sciences, University of Jeddah. Jeddah, Saudi Arabia. E-mail: ikhlasabdelaziz888@gmail.com membranes, and alar ligaments. It also allows the spinal component of the accessory nerve to pass into the skull. ${ }^{(2,3)}$ The configuration and size of the FM play an important role in the pathophysiology of various craniovertebral junction disorders.

Stenosis of the FM causes brainstem compression, which is often manifested by respiratory complications, lower cranial nerve dysfunction, upper and lower extremity paresis, hypo- or hypertonia, hyperreflexia, or clonus. ${ }^{(4,5)}$ Therefore, fundamental knowledge of this region's normal anatomy is important to clinicians when diagnosing patients. Radiological images such as those from computed tomography (CT) are widely used for FM measurements. ${ }^{(6)}$

In 1972, CT scans were commercially introduced in the radiology field, and as the first fully digital imaging device, it 
was truly revolutionary in diagnostic imaging. In conventional $\mathrm{CT}$, the X-ray tube and detector rotate around the patient while the table remains stationary. The X-ray beam is attenuated by absorption and scatter as it passes through the patient. With the detector measuring transmission, multiple measurements are taken from different directions as the tube and detector rotate. ${ }^{(6)}$ A computer reconstructs the image for a single slice, and the patient and table are then moved to the next slice position and the next image is obtained. To develop spiral (helical) CT images, the X-ray tube rotates continuously while the patient and table move through the scanner. ${ }^{(6)}$ Instead of individual slices, a block of data in the form of a helix is obtained. The scans can be performed during a single-breath hold, which reduces misregistration artifacts, which often occur when a patient has different respiratory depths. CT scanners with multiple rows of detectors allow the acquisition of multiple slices in one spiral acquisition, leading to many applications, such as multi-planer reconstruction, maximum intensity projection, three dimensions, and so on. ${ }^{(6)}$ In conjunction with fast rotation speeds, the volume coverage and speed performance are improved. ${ }^{(6)} \mathrm{CT}$ is a reliable modality that provides accurate bone measurements. In addition, it reduces the impact of overlapping structures and offers clear and precise images with high resolution. ${ }^{(7,8)}$

To the best of our knowledge, there are no anatomical studies of the FM in the Sudanese population. The aim of this study is to use CT images to characterize the FM in a sample of Sudanese participants and examine the effect on FM diameter of patient height and the diameter of the base of the skull to help predict pathological conditions according to organ size.

\section{Materials and Methods}

This study was conducted between January 2016 and March 2016 and included 50 patients $(60 \%$ male and $40 \%$ female, aged between 20 and 85 years, mean age of $49.24 \pm 19.69$ years) with normal cranial CT images. Participants with abnormal cranial CTs or poor quality images were excluded.

The current study adhered to the Declaration of Helsinki and Title 4, US Code of Federal Regulations, Part 46, Protection of Human Subjects.

Cranial CT scans were obtained from the scanner's local database and backed up on a compact disc from the CT library. The scans were performed using a multislice helical CT scanner (Toshiba 2009 model). Measurements were made with a Toshiba 16-slice and 4-slice Medical System. During CT scanning, patients were supine with their heads first and in a good position for the rest of the body. The FM measurements (sagittal and transverse) were obtained from reformatted axial sections (5 mm thickness, $150 \mathrm{kVp}, 200-230 \mathrm{mAs}, 1800$ AU window levels, and 35-45 s scan time) using helical CT scans All selected sections were parallel to the FM plane to ensure that the best images of the FM were included. The FM length diameter was recorded as the greatest antero-posterior dimension of the FM (i.e., the FM sagittal diameter [FMSD]). The FM width diameter was recorded as the greatest width of the FM (i.e., the FM transverse diameter [FMTD]) (Fig.1).

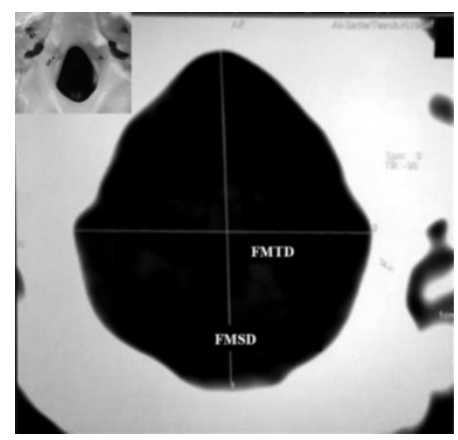

Fig. 1. FMTD and FMSD. ${ }^{(17)}$

The area of the FM was automatically obtained after tracing the bony margin of the FM on a CT image with a resolution of $1280 \times 1042$ (full-screen format), using a 3D program on the CT workstation (Fig.2).

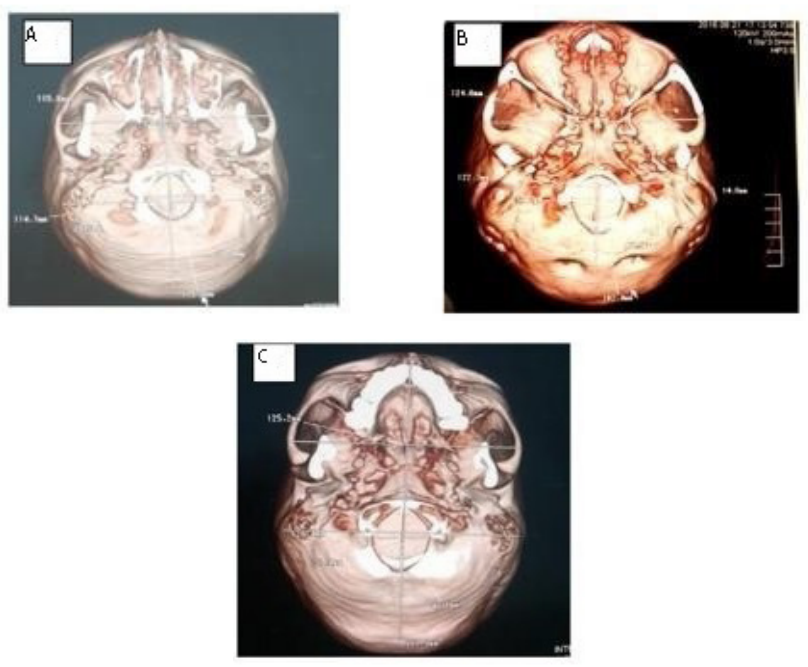

Fig. 2. CT images of the FM in 3D views: (A) A 47-year-old woman (the width and length of the base of the skull and FM; (B) A 25-year-old man (the width and length of the base of the skull and FM; (C) A 27-year-old woman (the width and length of the base of the skull and FM).

Methods for measuring the foramen magnum and skull base

The following descriptive and metric measurements were taken. ${ }^{(2)}$ FMSD included the direct distance from the basion to the opisthion. FMTD included the distance between the lateral margins of the FM at the points of greatest lateral curvature. The width of the base of the skull (BSW) was measured from the outside of the roots of the zygomatic processes at their deepest curvature to slightly anterior to the external auditory meatus. The length of the base of the skull (BSL) was measured from the distance between the anterior and posterior borders (Fig.1).

The data collection sheets completed for each subject included the following variables: sex, age, height, and FM and skull base diameters.

Statistical analysis was performed using the standard Statistical Package for the Social Sciences (SPSS Inc., Chicago, IL, USA) version 22 for Windows. The normality of distribution of continuous variables was tested by onesample Kolmogorov-Smirnov test. Continuous variables were 
presented as mean \pm standard deviation (SD). For data with normal distribution, inter-group comparisons were performed using Student's t-test. Pearson's correlation coefficient (r) was used to determine the strength of the relationship between the two continuous variables. A probability value of $\mathrm{P}<0.05$ was considered statistically significant.

\section{Results}

The following tables and figures present the data obtained from 50 patients with normal cranial CT scans at radiology departments. FMSD, including all subjects, ranged from $30 \mathrm{~mm}$ to $45 \mathrm{~mm}$ and from $26 \mathrm{~mm}$ to $35 \mathrm{~mm}$ for FMTD (Table 1). The mean FMSD and FMTD were $36.76 \pm 3.37 \mathrm{~mm}$ and $30.06 \pm 2.77 \mathrm{~mm}$, respectively (Table 1).

Table 1.

Statistical parameters for all patients

\begin{tabular}{|l|c|c|c|c|}
\hline Parameters & Mean & SD & Min & Max \\
\hline Age & 49.24 & 19.69 & 20 & 85 \\
\hline Height & 165.66 & 7.90 & 145 & 180 \\
\hline FMSD & 36.76 & 3.37 & 30 & 45 \\
\hline FMTD & 30.06 & 2.77 & 26 & 35 \\
\hline BSL & 178.98 & 7.92 & 160 & 195 \\
\hline BSW & 125.60 & 6.60 & 112 & 142 \\
\hline
\end{tabular}

This study compared the means and standard deviations of the FM diameters for males and females. The mean values of FMSD for female and male subjects were $35.80 \pm 2.88 \mathrm{~mm}$ and $37.41 \pm 3.27 \mathrm{~mm}$, respectively. There was no statistically significant difference between the two groups. The mean values of FMTD for female and male subjects were $28.8 \pm 1.96$ $\mathrm{mm}$ and $30.93 \pm 2.95 \mathrm{~mm}$, respectively (Tables 2 and 3 ). There was a statistically significant difference between the sexes.

Table 2.

Statistical parameters for females

\begin{tabular}{|l|c|c|c|c|}
\hline Parameters & Mean & SD & Min & Max \\
\hline Age & 48.55 & 19.57 & 20 & 84 \\
\hline Height & 161.70 & 7.59 & 145 & 175 \\
\hline FMSD & 35.80 & 2.88 & 31 & 41 \\
\hline FMTD & 28.80 & 1.96 & 26 & 33 \\
\hline BSL & 174.15 & 7.58 & 160 & 187 \\
\hline BSW & 120.85 & 5.02 & 112 & 133 \\
\hline
\end{tabular}

Table 3.

Statistical parameters for males

\begin{tabular}{|l|c|c|c|c|}
\hline Parameters & Mean & SD & Min & Max \\
\hline Age & 49.70 & 20.30 & 22 & 85 \\
\hline Height & 168.30 & 7.06 & 155 & 180 \\
\hline FMSD & 37.41 & 3.57 & 30 & 44 \\
\hline FMTD & 30.93 & 2.95 & 26 & 35 \\
\hline BSL & 182.2 & 6.45 & 169 & 195 \\
\hline BSW & 128.77 & 5.59 & 118 & 142 \\
\hline
\end{tabular}

FMSD and FMTD for all patients are represented in Figures 3 and 4, respectively. Figures 5 and 6 include the BSL and BSW for all patients, respectively. A weak direct correlation was found between FMSD and BSL ( $\mathrm{r}=0.177)$, indicating that the diameter of the base of the skull is related to the measurement of the FM. Weak direct correlations were also found between patient height and FMSD ( $r=0.023)$ and patient height and BSL $(\mathrm{r}=0.044)$.

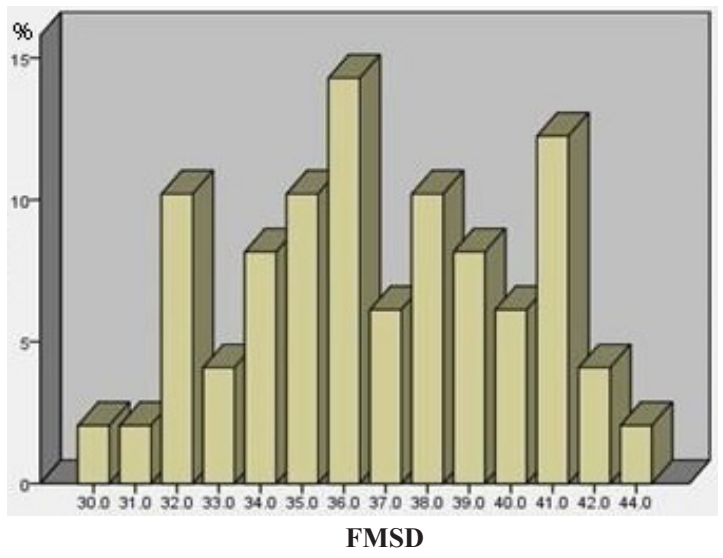

Fig. 3. The distribution of FMSD for all patients.

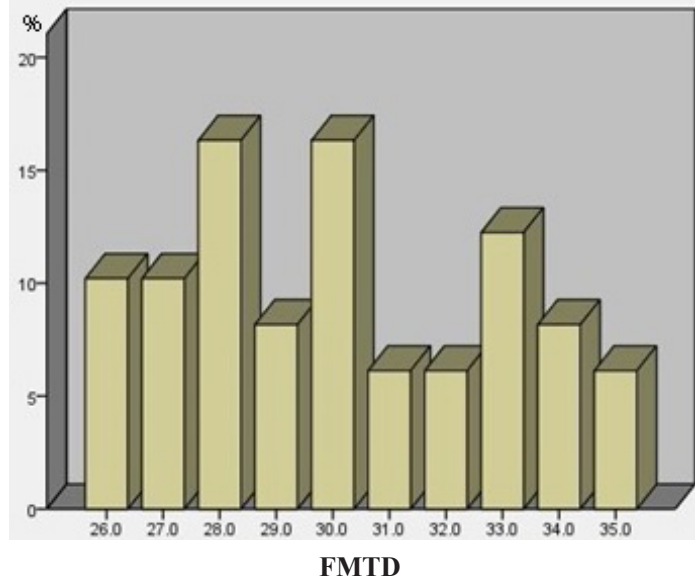

Fig. 4. The distribution of FMTD for all patients.

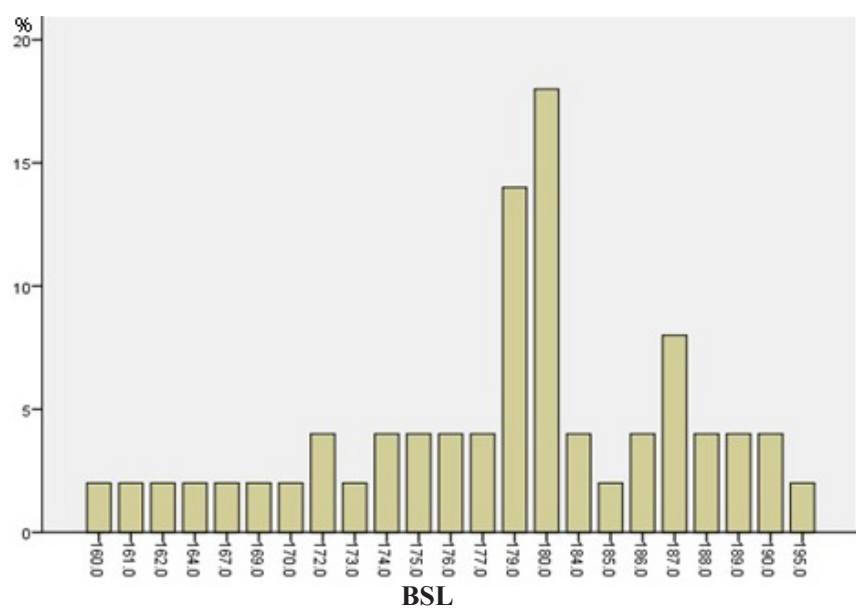

Fig. 5. The distribution of BSL for all patients. 


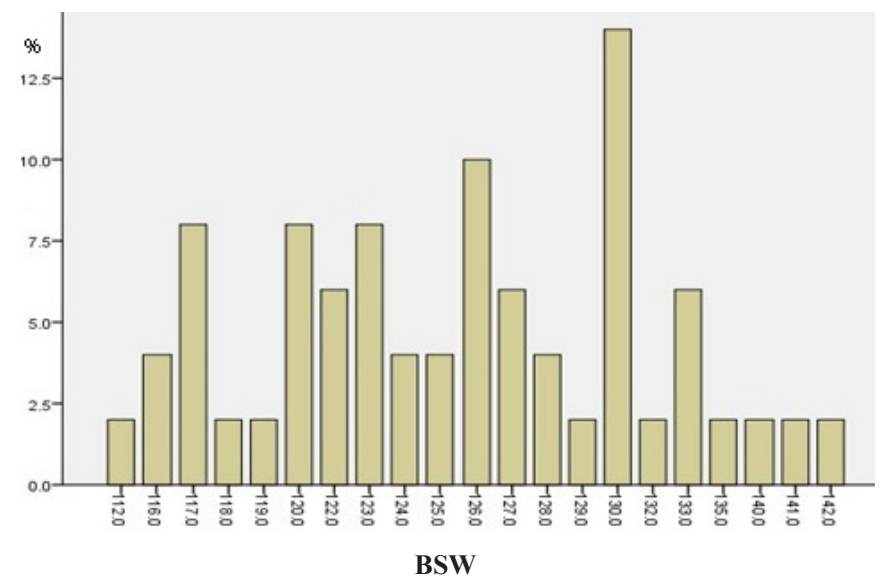

Fig. 6. The distribution of BSW for all patients.

\section{Discussion}

This study aimed to characterize the dimensions of the FM in a Sudanese sample using CT images. The FM is vital in identifying the gender of unknown skeletal remains, a process particularly important in forensic radiology because remains are often compromised by fragmentation damages that affect the accuracy of sex determination. ${ }^{(9)}$ Because of its anatomical position, the FM is protected by the occipital bone and has an increased potential for survival, making it ideal for determining sex. ${ }^{(10)}$

The results of the current study show that although the FM dimensions (length and width) for males were larger than for females, this difference was not statistically significant. These results concur with previous studies. ${ }^{(9-11)}$ FMSD and FGTD were $36.11 \mathrm{~mm}$ and $29.56 \mathrm{~mm}$ in males and females, respectively. FMSD and FMTD showed no difference across subjects from 20 to 79 years of age, which is similar to the findings of this study. ${ }^{(1)}$ However, our results confirm the presence of sex differences in FM dimensions in a Sudanese sample.

Toneva et al. ${ }^{(12)}$ compared the results of 20 previous studies and found that the FM dimensions in Bulgarian males are very similar to those of Turkish, Greek, and Spanish males. However, they also found that the FM in Bulgarian females is slightly longer and narrower than in Turkish, Greek, and Spanish females. Our FM measurements were similar to those of an Egyptian population study, which found no statistically significant sex difference. ${ }^{(3)}$ Gruber et al. stated that FM sizes are relatively similar for most of the recently studied populations. ${ }^{(13)}$ Therefore, FM size is not perfect for ethnicity identification. ${ }^{(13)}$ The configuration of the FM created from developmental changes affects the morphology of the four parts of the intraoccipital synchondroses and the occipital bone, and in modern humans the dominant FM shape is oval or oval to round. ${ }^{(14)}$ Sudanese, Polish, and Greek populations more frequently demonstrate an oval shape ${ }^{(14,15)}$ and a round shape is more frequently found in Turkish and Swiss populations. ${ }^{(15,16)}$

This study attempted to find a correlation between FMSD, BSL, and patient height. There was a weak correlation among the three measurements. The main limitation of this study is its small sample size, but we suppose that expanding the sample size may not lead to finding a significant difference in FM size in a larger population.

In conclusion, the FM dimensions in Sudanese males were greater than in females. There was a direct relationship between FMSD and BSL, but this correlation was weak. The effect of the diameter of the base of the skull on the FM diameter was very weak. In addition, there was a relationship between FM diameter and patient height, although this correlation was weak. There was no influence of patient height on the measurement of FM.

\section{Competing Interests} interests.

The authors declare that they have no competing

\section{Acknowledgements}

We are extremely grateful to many people who supported us during the preparation of this study. We would like to express our deep gratitude to Dr. Huzaifa Mohamed Elsanosi for his support and guidance. Our thanks also go to the staff of Radiology Department of Abdoon SidAhmed Diagnostic Center.

\section{References}

1. Ellis H. Clinical anatomy, $3^{\text {rd }}$ edn. J Anat. 1997;190(Pt4):631-632.

2. Iscan MY, Steyn M. The human skeleton in forensic medicine. Charles C Thomas Publisher; 2013.

3. Lashin HI, Eldeeb BS, Ghonem MM. Sex identification from foramen magnum using computed tomography scanning in a sample of Egyptian population. J Forensic Leg Med. 2019;19:100341.

4. Arnautović KI, Al-Mefty O, Husain M. Ventral foramen magnum meninigiomas. J Neurosurg. 2000;92(1 Suppl):71-80. doi:10.3171/spi.2000.92.1.0071

5. Bagley CA, Pindrik JA, Bookland MJ, Camara-Quintana JQ, Carson BS. Cervicomedullary decompression for foramen magnum stenosis in achondroplasia. J Neurosurg. 2006;104(3 Suppl):166-172. doi:10.3171/ped.2006.104.3.166

6. Kalender WA. Computed tomography: fundamentals, system technology, image quality, applications. John Wiley \& Sons; 2011.

7. Dammann F, Bootz F, Cohnen M, Hassfeld S, Tatagiba M, Kösling S. Diagnostic imaging modalities in head and neck disease. Dtsch Arztebl Int. 2014;111(23-24):417-423. doi:10.3238/arztebl.2014.0417

8. Ekizoglu O, Er A, Bozdag M, et al. Sex estimation of the tibia in modern Turkish: A computed tomography study. Leg Med (Tokyo). 2016;23:89-94. doi:10.1016/j. legalmed.2016.10.004

9. Edwards K, Viner M, Schweitzer W, et al. Sex determination from the foramen magnum. J Forensic Leg Med. 2013;1:186-192.

10. Gapert R, Black S, Last J. Sex determination from the foramen magnum: discriminant function analysis in an 
eighteenth and nineteenth century British sample. Int J Legal Med. 2009;123(1):25-33. doi:10.1007/s00414-008-0256-0

11. Catalina-Herrera CJ. Study of the anatomic metric values of the foramen magnum and its relation to sex. Acta Anat (Basel). 1987;130(4):344-347. doi:10.1159/000146468

12. Toneva D, Nikolova S, Harizanov S, Georgiev I, Zlatareva D, Hadjidekov V, et al. Sex estimation by size and shape of foramen magnum based on CT imaging. Leg Med (Tokyo). 2018;35:50-60. doi:10.1016/j.legalmed.2018.09.009

13. Gruber P, Henneberg M, Böni T, Rühli FJ. Variability of human foramen magnum size. Anat Rec (Hoboken). 2009;292(11):1713-1719. doi:10.1002/ar.21005

14. Burdan F, Szumiło J, Walocha J, Klepacz L, Madej B, Dworzański W, Klepacz R, et al. Morphology of the foramen magnum in young Eastern European adults. Folia Morphol (Warsz). 2012;71(4):205-216.

15. Natsis K, Piagkou M, Skotsimara G, Piagkos G, Skandalakis P. A morphometric anatomical and comparative study of the foramen magnum region in a Greek population. Surg Radiol Anat. 2013;35(10):925-934. doi:10.1007/s00276-013-1119-z 16. Akay G, Güngör K, Peker İ. Morphometric analysis of the foramen magnum using cone beam computed tomography. Turk J Med Sci. 2017;47(6):1715-1722. Published 2017 Dec 19. doi:10.3906/sag-1607-127

17. Uthman AT, Al-Rawi NH, Al-Timimi JF. Evaluation of foramen magnum in gender determination using helical CT scanning. Dentomaxillofac Radiol. 2012;41(3):197-202. doi: $10.1259 / \mathrm{dmfr} / 21276789$. 